\title{
Inhibition of Biofilms by Non-Thermal Plasma Treated Novel Solutions
}

\author{
Utku K. Ercan'1, Siddharth S. Joshi', Adam Yost'1, Natalie Gogotsi', Sean 0’Toole1, \\ Michelle Paff ${ }^{1}$, Eric Melchior ${ }^{1}$, Suresh G. Joshi1 ${ }^{1,2 *}$ \\ ${ }^{1}$ Department of Surgery, Drexel University College of Medicine, Philadelphia, Pennsylvania, USA \\ ${ }^{2}$ Department of Microbiology and Immunology, Drexel University College of Medicine, Philadelphia, \\ Pennsylvania, USA \\ Email: ${ }^{*}$ Suresh.Joshi@Drexelmed.edu, ${ }^{*}$ Surejoshi@yahoo.com
}

Received 18 October 2014; revised 19 November 2014; accepted 3 December 2014

Copyright (C) 2014 by authors and Scientific Research Publishing Inc.

This work is licensed under the Creative Commons Attribution International License (CC BY).

http://creativecommons.org/licenses/by/4.0/

(c) (i) Open Access

\section{Abstract}

Biofilms act as a reservoir of infection, and periodically release cells in vicinity that are capable of developing new biofilm colonies and disseminate infection. Many chronic bacterial infections are serious that are associated with biofilms and have high morbidity and mortality, partly due to their higher resistance to antimicrobial agents, and partly due to lack of strong biocides which can efficiently treat and inhibit biofilm formation. We recently demonstrated that nonequilibrium non-thermal dielectric-barrier discharge plasma (Plasma) can also be applied to control pathogens via applying treated-liquids, and these liquids acquire broad-spectrum antimicrobial properties. In present studies we demonstrated a range of plasma-activated simple chemical solutions which significantly inhibited biofilm formation by multidrug-resistant bacterial pathogens. Plasma-activated methionine solution exhibited strong inhibitory activity against the biofilms of carbapenem-resistant Acinetobacter baumannii, methicillin-resistant Staphylococcus aureus, metallo- $\beta$-lactamase (NDM1)-positive Klebsiella pneumoniae, and Enterococcus faecalis, and prevented the formation of biofilms by about $\mathbf{7 0 \%}$ as compared to untreated controls in single exposure. In addition to inhibition of biofilm formation, a complete inactivation of biofilm-embedded bacterial cells was observed in less than $\mathbf{3 0}$ minute's exposure to candidate plasma-activated methionine solution. These findings suggest that plasma-activated solutions have a potential to prevent biofilm formation, and as biofilm inhibitor.

\section{Keywords}

Acinetobacter baumannii, Antibacterial Solution, Antibiofilm Agent, Biofilm, MRSA, Nonthermal Plasma

\footnotetext{
${ }^{*}$ Corresponding author.
}

How to cite this paper: Ercan, U.K., Joshi, S.S., Yost, A., Gogotsi, N., O’Toole, S., Paff, M., Melchior, E. and Joshi, S.G. (2014) Inhibition of Biofilms by Non-Thermal Plasma Treated Novel Solutions. Advances in Microbiology, 4, 1188-1196. 


\section{Introduction}

Biofilms have a huge impact on bacterial infections both, acute and chronic. The growing importance of biofilm establishes that it is a predominant mode of growth of bacteria in almost all different environments, and about 99\% of the bacteria survive in biofilm form of life [1] [2]. In addition to virulence, biofilm is a survival strategy for many pathogens, wherein the planktonic form of bacteria intentionally forms biofilm under unfavorable or harsh conditions. Bacterial cells in biofilm slow down their metabolism, reduce energy consumption, protect from external environmental factors (resist antibiotics, biocides and desiccation), and act as a reservoir of propagating cells (by intermittently releasing bacterial cells back to free living planktonic form) [3] [4]. Millions of bacterial cells are present in biofilms in well-organized microcolonial communities within their own secreted product, the extracellular polysaccharides, and their genetic program is tightly regulated. Continued release of pathogenic bacteria cells lead to spread of infection inside host, and transmission of infection either from carrier to new host or environment to host. Therefore, control of such biofilms is an important disruption step in dissemination of such pathogens.

All artificial surfaces used in clinical practice and public health are prone to develop biofilm, and therefore represent a source/risk of infection. To prevent outbreaks and dissemination of infection, efficient control of bacterial biofilms is an essential step. Chemical and physical disinfection methods are widely used to inactivate sessile biofilm forms of microorganisms, with variable efficacies. With the rise of multidrug resistant bacterial pathogens, and their clonal expansion within biofilm, their control became a challenge for clinicians and associated healthcare providers. Most of the currently available biocidal agents are either highly cytotoxic or not efficient in complete inactivation of pathogen embedded in biofilm or their prevention biofilm [5]-[7]. Many antimicrobial agents in their sublethal as well as optimal doses selected resistant mutants, and thus failed to efficient eradication or inhibition of such pathogen, leaving a clear need for antibiofilm agents that can efficiently inhibit biofilm, and inactivate embedded pathogens from formed biofilms.

Earlier, our laboratory has demonstrated that both direct exposure of biofilms, and indirectly exposed biofilms to nonthermal dielectric discharge-barrier plasma (Plasma)-treated fluids significantly inactivate bacteria in their planktonic and biofilm forms [8]. Plasma-treated fluids behave as an oxidant, and inactivate bacterial cells by mounting intracellular oxidative stress [9]. Depending on the type of solution being treated, the treated fluid generates a variable pool of oxidative and/or nitrosative stress in bacterial cells, and possibly target multiple sites for oxidation. In this proof of concept study, nonthermal plasma-activated variety of solutions were generated at normal atmospheric air (without any special gas or additional pressure), and tested for their novel broad-spectrum biofilm inhibition and antibiofilm activity against the biofilms of multidrug resistant virulent pathogens to explore possibility of use as biocidal agents for surface disinfection.

\section{Materials and Methods}

\subsection{Bacterial Strains and Culture Conditions}

The strains used this study were: methicillin-resistant Staphylococcus aureus (MRSA) (USA100) BAA-1680, Klebsiella pneumonia (NDM1+) BAA-2146, and clinical isolate of Enterococcus faecalis ATCC29212 (all from, American Type Culture Collection, Manassas, VA) and carbapenem-resistant MDR Acinetobacter baumannii (CRAB) (a local clinical isolates \# 22 from our laboratory). The cultures were developed by inoculation of a single isolated colony from overnight grown trypticase soy agar (TSA) plate into $10 \mathrm{ml}$ of trypticase soy broth (TSB) and incubated at $37^{\circ} \mathrm{C}$ in stationary incubator. On following day, overnight cultures were used for antimicrobial assays and seeding biofilms.

\subsection{Chemical Solutions Used in Treatment}

Glucose, cysteine, glycine, proline, methionine, threonine, glutamate, arginine, and heparin (Sigma Chemical Co., St. Louis, MO) were used. All solutions used for treatment were tested at concentrations of $1 \mathrm{mM}$ through $10 \mathrm{mM}$, and were prepared in phosphate-buffered saline (PBS; $150 \mathrm{mmol} / \mathrm{L}$ sodium chloride and $150 \mathrm{mmol} / \mathrm{L}$ sodium phosphate, $\mathrm{pH} 7.2$, at $25^{\circ} \mathrm{C}$ ) using deionized water (MP Biomedicals Inc., Solon, OH). Solutions were freshly prepared, $0.22 \mu$ filter sterilized, aseptically handled, and aliquot either used fresh or stored at $-20^{\circ} \mathrm{C}$ for subsequent experiments. 


\subsection{Plasma Setting and Fluid Treatment Conditions}

Nonthermal plasma generator used in these studies is showed in Figure 1; and this in-house built electrode and fluid chamber system is reported earlier by our laboratory [9] [10]. The parameters were set to $31.4 \mathrm{kV}, 0.29$ W/ $\mathrm{cm}^{2}, 1500 \mathrm{~Hz}$ pulse frequency, pulse duration 10 microseconds, $2 \mathrm{~mm}$ of gap between the surface of fluid and DBD electrode. One milliliter of chemical solution was treated for 15 seconds through 180 seconds or left untreated (zero (0) second), and used freshly. A prototype post-treated methionine (5 mM) solution was held at room temperature for over time (up to $2 \mathrm{~h}$ ), and then used for biofilm-embedded cell survival assay, to find out whether their anti-biofilm potency is compromised/reduced.

\subsection{Biofilm Inhibition Assay}

Biofilms were developed in 96 well polystyrene microtiter plates (Corning Inc., Corning, NY). Briefly, the overnight cultures were diluted to 1:100 in TSB, and 50 ul transferred to each well of 96 well plates containing $50 \mathrm{ul}$ of either untreated or plasma-treated chemical solution. The plates was gently whirled manually, and held at room temperature for $60 \mathrm{~min}$ (to interact with cells), after which $100 \mathrm{ul}$ of TSB was added and incubated for $24 \mathrm{~h}$ at $37^{\circ} \mathrm{C}$ in stationary incubator. On the following day, all the wells were washed gently with PBS for three times, and drained off the traces of PBS solution by pressing inverted plate again a pad of paper towels. Aliquots of $200 \mathrm{ul}$ of $0.1 \%$ Safranin was added to each well and held for biofilm staining for $15 \mathrm{~min}$ at room temperature, after which the wells rinsed three times gently with PBS and air-dried. Biofilm mass was visually inspected, and then after adding $200 \mathrm{ul}$ of $33 \%(\mathrm{v} / \mathrm{v})$ acetic acid to dissolve stain in it, and quantified by taking absorption at $492 \mathrm{~nm}$ in microplate reader (Synergy Mx; BioTek), as described [8] [11] [12]. The assays were repeated for 3 to 5 times, had a similar trend, and average is taken to plot graphs. Likewise, the assays carried out for each test sample against the biofilm of MRSA, A. baumannii, K. pneumonia and E. faecalis.

\subsection{XTT Cell Viability Assay}

For each assay, fresh XTT (2,3-bis-(2-methoxy-4-nitro-5-sulfophenyl)-2H-tetrazolium-5-carboxanilide) reagent solution was prepared, and assayed as described earlier [8] [13]. In brief, after appropriate treatment or no treatment (with plasma treated or untreated solution), the biofilms were rinsed gently thrice with PBS to remove loosely adhered (non-biofilm) organisms, and 200 ul XTT reagent was added to each well, mixed gently, and plate incubated at $37^{\circ} \mathrm{C}$ for 2 hours. The orange colored supernatant metabolic product $(100 \mu \mathrm{L})$ was measured by reading absorption at $492 \mathrm{~nm}$ using a microtiter plate reader (BioTek). The readings were normalized, and percent surviving cells were calculated against untreated samples. The assays were carried out for each solution against various biofilms mentioned above, and were repeated three times.

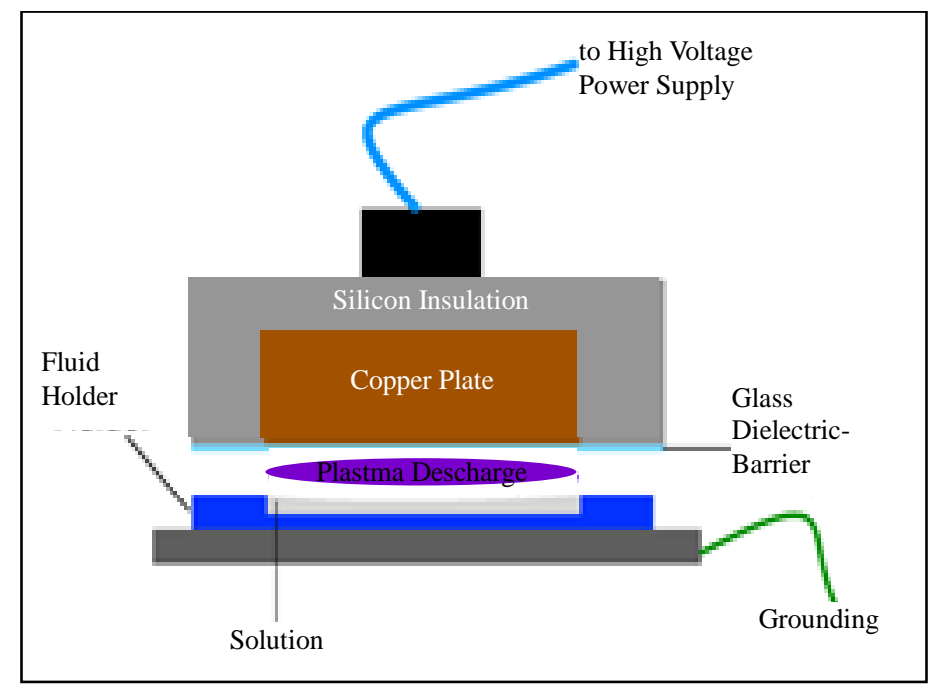

Figure 1. A schematic diagram of non-thermal dielectric-barrier discharge plasma set-up used in this study. 


\subsection{Antimicrobial Activities against Planktonic Cells}

To investigate the antibacterial activities of plasma-treated methionine solution, the planktonic growth of carbapenem-resistant $A$. baumannii in the presence and absence of prototype plasma-treated methionine $(5 \mathrm{mM})$ over time was studied. An overnight grown CRAB culture in TSB was adjusted to an optical density at $600 \mathrm{~nm}$ $\left(\mathrm{OD}_{600}\right)$ to 0.2 , and then $100 \mathrm{ul}$ transferred to each well of 96-well plate, containing $100 \mathrm{ul}$ of plasma-treated or untreated methionine solution (thus final 1:1 ratio) and held at room temperature for $15 \mathrm{~min}$, after which colony count assays performed using standard serial dilution technique. The inoculated TSA plates were incubated at $37^{\circ} \mathrm{C}$ for $24 \mathrm{~h}$ and the colonies counted to calculate total number of log reduction in CFU/ml. The TSA plate which did not show any growth was incubated for further $72 \mathrm{~h}$ to confirm complete inactivation.

\subsection{Live/Dead Assay and Effect on Preformed Biofilms}

Besides inhibition of biofilm formation in presence or absence of treated methionine, the killing/ inactivation of bacteria in preformed biofilms by treated methionine solution was also investigated using live/dead staining [6] [8]. In brief, biofilms (of carbapenem-resistant $A$. baumannii) were allowed to form in 96-well plate for $24 \mathrm{~h}$ by incubating at $37^{\circ} \mathrm{C}$ in stationary incubator, after which the biofilms were washed thrice gently with sterile PBS, and exposed to either plasma-treated or untreated methionine solution $(5 \mathrm{mM})$ for $15 \mathrm{~min}$ at room temperature. The fluid component was gently aspirated and the biofilms rinsed thrice with PBS before staining. The biofilms were stained with Live/Dead assay kit (Life Technologies, Grand Island, NY) as per manufacturer's direction, and fluorescence microscopic images were taken using Fluorescence Microscope (Olympus, Shinjuku, Tokyo, Japan), analyzed using Adobe Photoshop CS version (Adobe, Inc., San Jose, CA), and saved as TIFF files.

\subsection{Statistical Analysis}

Experimental data was analyzed using Prism software 4.03 for Windows (GraphPad, San Diego, CA), and standard deviations were calculated from minimum 3 sets of experiments. The experiments were repeated in triplicate. The $P$ value was derived using pair comparisons between 2 bacterial groups using Student $t$ test and 2-way analysis of variance for multiple comparisons wherever applicable (* indicates $P$ value as a statistically significant $(P \leq 0.05))$. Bar represents standard deviation (SD).

\section{Results and Discussion}

Nonthermal nonequilibrium plasma generated at room air has been applied in various forms, and evaluated for a range of biomedical applications [14], including clinical practice, and disinfection and sterilization [15] [16]. Inactivation of bacterial pathogens in their planktonic and biofilm forms has been demonstrated by many investigators, including our laboratory [8] where direct plasma treatment used successfully. Biofilm is a special form of bacterial reservoir that intermittently acts as a source of infection outbreak by releasing bacterial cells, and is more resistant to antimicrobial and biocidal agents than planktonic form counterpart, and often requires about 100 to 1000 time more antibiotics to inactivate embedded pathogens. Surface disinfectants have a major role in eradication of biofilms in this regard. Plasma can either be applied directly to biofilm bearing surface [8] or biofilm can be treated with plasma-treated fluids to inactivate embedded pathogens [9]. Biofilm curing or treatment has been demonstrated using different plasma systems by many investigators [16]-[21], but not the system, set up, and approach we used. This study explores for the first time the use of nonthermal atmospheric plasma-treated solutions in inhibition of biofilm formation (in addition to treating (preformed) biofilm) with a range of plasma-activated antibiofilm solutions.

Overall, the inhibition of biofilm formation was found plasma treatment time dependent during testing of biofilms of MRSA, CRAB, NDM1 + K. pneumoniae and E. faecalis (Figure 2). When we increased treatment time, we saw significantly more inhibition of biofilm production $\left({ }^{*} P<0.05\right.$ against plasma untreated biofilms; 0 minute). This is probably due to the increasing amount of plasma energy $\left(\mathrm{J} / \mathrm{cm}^{2}\right)$ deposition in solution, and the associated chemical changes in solution that underlie. Our earlier observation demonstrated that response of biofilm eradication to plasma-activated fluid is exposure-time-dependent [9]. This trend was also observed during biofilm inhibition studies. The plasma-treated methionine solution was more efficient, and significantly inhibited biofilms of all the pathogens tested (Figure 2(a)) Treated threonine, treated glucose, and treated cysteine solutions were more efficient against MRSA and E. faecalis (both Gram-positive organisms) than Gram-negative 

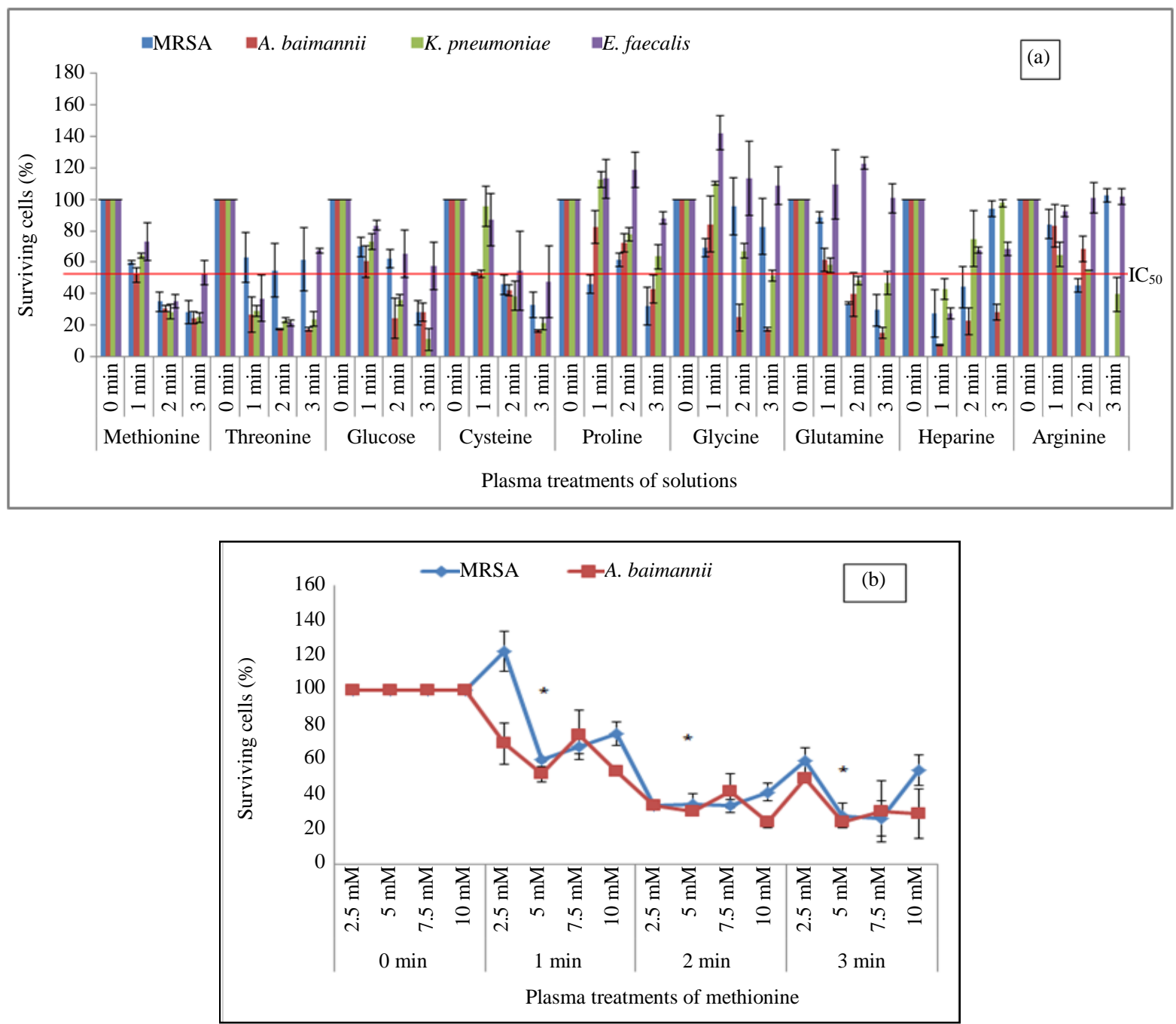

Figure 2. Screening of various non-thermal plasma-treated chemical solutions (a) (5 mM; predetermined) for inhibition of MDR bacterial biofilms of methicillin-resistant $S$. aureus USA300, carbapenem-resistant $A$. baumannii, NDM1-positive $K$. pneunomiae, and E. faecalis. A significant inhibition of biofilm is seen by end of plasma treatment of the solutions as compared to corresponding untreated controls (0 minutes). (b) Non-thermal plasma-activated methionine concentration-dependent inhibition of representative biofilms of methicillin-resistant S. aureus and carbapenem-resistant A. baumannii (*, $P<$ 0.05; bar, SEM).

pathogens. Treated glutamine and treated glycine solutions were more effective against $E$. faecalis. A known lock solution of heparin was also activated with plasma treatment, where we observed a significantly more biofilm inhibitory activity by 1 min treated solution as compared to untreated heparin solution. Heparin is a most popular traditional lock solution for intravenous infusion set but originally has negligible antimicrobial/antibiofilm activity [22]-[24]. Thus, plasma-activated solutions were broad-spectrum in nature, and having a potential to develop as antimicrobial lock solutions and biocidal agents. In addition, our pilot study demonstrated that the doses of plasma-treated fluid required for bacterial inactivation are much lower than the doses leading to cytotoxicity in [25], and therefore appropriate to explore for further applications.Inhibitory concentration of plasma-treated solutions that inhibited $50 \%$ of biofilm formation $\left(\mathrm{IC}_{50}\right)$ was variable for different biocidal solutions, and mostly found between plasma treatment times of 1 minute to 2 minutes.

Plasma-treated methionine solution was further tested for concentration-dependent kinetics, as it showed an effective inhibition of biofilms of all pathogens during preliminary study, and hence was ideal candidate. We found $5 \mathrm{mM}$ methionine as optimal concentration for inhibition of biofilms. Almost similar responses were seen against MRSA and CRAB biofilms formation wherein the treated methionine solution (5 mM) significantly in- 
hibited biofilms as compared to plasma untreated solution $(P=<0.05)$ (Figure 2(b)). We speculate that the chemical species generated during plasma treatment of such solution may be proportionally increasing to the point that inhibits biofilm formation significantly.

Live/Dead assay is widely used to demonstrate whether cell's membrane integrity is compromised during cellular inactivation [8] [9] [26]. Figure 3(a) represent fluorescence microscopic images of untreated and treated biofilms that are stained with live/dead staining (Green, live cells and red, dead cells in biofilm), and Figure 3(b) is a percent of biofilm-embedded viable cells. Together, Figure 3 indicates that plasma-treated methionine (5 $\mathrm{mM}$ ) reduce membrane potential and eventually breach in continuity, a significant inactivation of $A$. baumannii cells in their biofilm-embedded form, and that the response is plasma-treatment dependent. This explains that treated methionine not only inhibit biofilm formation but also inactivate MDR pathogen such as embedded CRAB even in preformed biofilm.
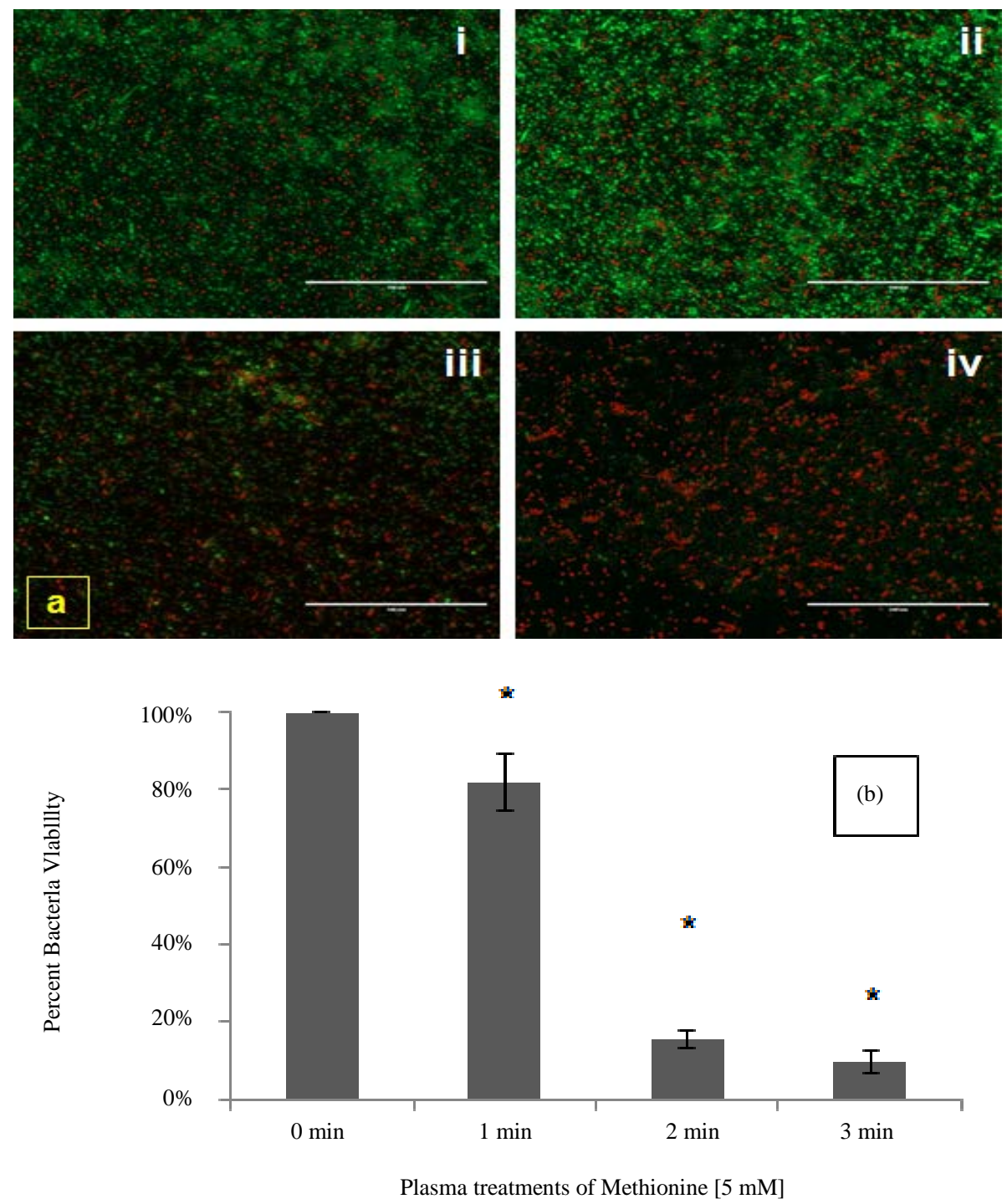

Figure 3. Live/Dead assay, showing the plasma-treatment-dependent antibiofilm activity of plasma-activated methionine (5 mM). (a) Representative fluorescence microscopic images of carbapenem-resistant Acinetobacter baumannii biofilm (24 h matured) responses to 0 min (i), $1 \mathrm{~min}$ (ii), $2 \mathrm{~min}$ (iii), and $3 \mathrm{~min}$ (iv) of plasma-treated methionine. (Scale bar, $100 \mathrm{um}$ ). (b) A graph showing significant percent of inactivation of biofilm-embedded cells as compared to control (0 $\mathrm{min})$ as observed (in Figure 3(a)). Green fluorescing cells, live cells; red fluorescing cell, dead cells in biofilm $(*, P<0.05$; bar, SEM). 

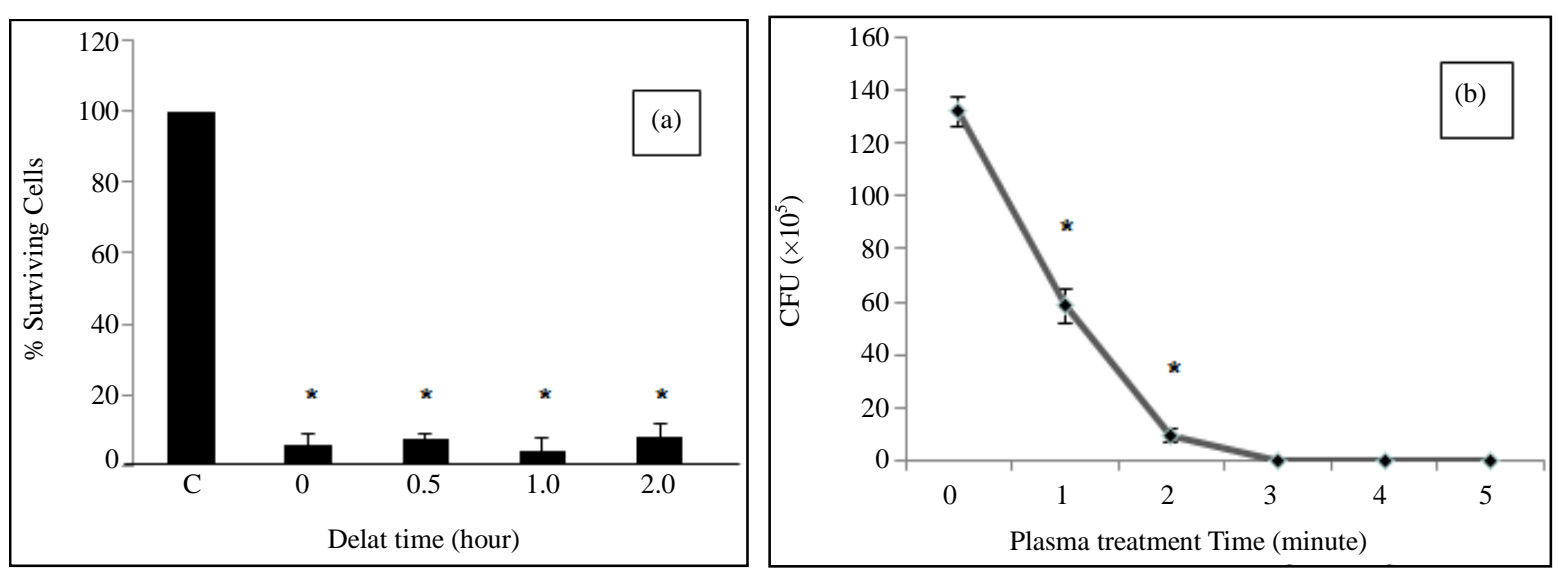

Figure 4. Nonthermal plasma-activated methionine-mediated inactivation of carbapenem-resistant A. baumannii (CRAB) cells embedded in biofilms, wherein treated solution was held up (delayed) to $2 \mathrm{~h}$ at room temperature before exposing biofilms. The percent biofilm-embedded surviving cells were determined by XTT cell viability assay (a) (c untreated control). Plasma-activated methionine was able to completely inactivate planktonic CRAB cells during colony assay (b) $(*, P<0.05$; bar, SEM).

To confirm that the pathogens embedded in preformed biofilms are inactivated, we also performed XTT assays that measures cell viability and cellular respiration. The plasma-treated methionine solution was able to inactivate embedded CRAB in their biofilm form. Holding of post-treated methionine for up to $2 \mathrm{~h}$ (before exposing to bacteria) did not compromise solution's biofilm inhibitory activity (Figure 4(a)). As observed in Figure 4(b), a complete inactivation of pathogen is possible at as low as 3 min treatment time and 15 min exposure of planktonic pathogen to activated methionine solution. These findings resemble to our recent report wherein plasma-treated water, PBS and N-acetyl cysteine solutions (thus chemically different solutions) were investigated [9]. A plasma treatment generated certain chemical changes in terms of oxidative and nitrosative stressinducing species or the products thereof would be modulating pathogen's responses of biofilm formation and inactivation. Further studies are undertaken to chemically correlate the changes and their influence on biofilm responses.

Biofilms are tightly linked with man's failure to control infection, even by the strong antibiotics and biocides that are effective against free living planktonic form of bacteria [27]. Therefore one of the major goals in the field of healthcare is to attempt to develop new strategies and solutions which are capable of reducing and/ or inhibiting bacterial biofilms that are difficult to eradicate. It is alarming to implement such strategies before resistant clones are emerged by less effective biocides [27]. Earlier we reported that exposure to sublethal (inadequate) doses of plasma is likely to lead to dormancy instead of complete inactivation of planktonic bacteria [28]. Thus, like that of other biocidal agents, adequate exposure of biofilms to plasma-treated fluid is advisable. An advantage of nonthermal plasma activated solution is that it targets number of specific cellular targets that exhibits multiple physiological activities [8] [9] [26]. Therefore development of resistance against such biocidal agent is less likely. Our preliminary data on (another plasma-treated fluid and) animal studies indicates no acute systemic toxicity, and an excellent wound healing [25]. Further studies related to catheter-associated infection and biofilm, wound biofilm, and host tissues and cellular responses are required to understand the detailed mechanisms of proposed antibiofilm solutions.

\section{Conclusion}

In conclusion, for the first time we correlate plasma-treated solutions with inhibition of biofilm formation. The findings of this proof of concept study demonstrate a potential for nonthermal, normal atmospheric plasma-activated solution (such as methionine solution) as broad-spectrum antibiofilm solution that can inhibit biofilm formation on inanimate surfaces.

\section{Conflict of Interest}

None to declare. 


\section{Acknowledgments}

Utku Ercan was a PhD student on scholarship from Ministry of Education, Government of Turkey, Adam Yost was a PhD student from Biomedical Engineering Program of Drexel University, Siddharth Joshi and Sean O’Toole were research co-op students, Natalie Gogotsi was a research volunteer, Michelle Paff was a medical student, and Eric Melchior was master of medical science student. The work was carried out through intramural support by Drexel University College of Medicine.

\section{References}

[1] Costerton, J.W., Cheng, K.J., Geesey, G.G., Ladd, T.I., Nickel, J.C., Dasgupta, M. and Marrie, T.J. (1987) Bacterial Biofilms in Nautre and Disease. Annual Review of Microbiology, 41, 435-464. http://dx.doi.org/10.1146/annurev.mi.41.100187.002251

[2] Conrad, J.C. (2012) Physics of Bacterial Near-Surface Motility Using Flagella and Type IV pili: Implications for Biofilm Formation. Research in Microbiology, 163, 619-629. http://dx.doi.org/10.1016/j.resmic.2012.10.016

[3] Donlan, R.M. and Costerton, J.W. (2002) Biofilms: Survival Mechanisms of Clinically Relevant Microorganisms. Clinical Microbiology Reviews, 15, 167-193. http://dx.doi.org/10.1128/CMR.15.2.167-193.2002

[4] Wolcott, R.D. and Ehrlich, G.D. (2008) Biofilms and Chronic Infections. JAMA: The Journal of the American Medical Association, 299, 2682-2684. http://dx.doi.org/10.1001/jama.299.22.2682

[5] Leung, C.Y., Chan, Y.C., Samaranayake, L.P. and Seneviratne, C.J. (2012) Biocide Resistance of Candida and Escherichia coli Biofilms Is Associated with Higher Antioxidative Capacities. The Journal of Hospital Infection, 81, 79-86. http://dx.doi.org/10.1016/j.jhin.2011.09.014

[6] Smith, K. and Hunter, I.S. (2008) Efficacy of Common Hospital Biocides with Biofilms of Multi-Drug Resistant Clinical Isolates. Journal of Medical Microbiology, 57, 966-973. http://dx.doi.org/10.1099/jmm.0.47668-0

[7] O’Toole, G.A. (2002) Microbiology: A Resistance Switch. Nature, 416, 695-696. http://dx.doi.org/10.1038/416695a

[8] Joshi, S.G., Paff, M., Friedman, G., Fridman, G., Fridman, A. and Brooks, A.D. (2010) Control of Methicillin-Resistant Staphylococcus aureus in Planktonic Form and Biofilms: A Biocidal Efficacy Study of Nonthermal DielectricBarrier Discharge Plasma. American Journal of Infection Control, 38, 293-301. http://dx.doi.org/10.1016/j.ajic.2009.11.002

[9] Ercan, U.K., Wang, H., Ji, H.F., Fridman, G., Brooks, A.D. and Joshi, S.G. (2013) Nonequilibrium Plasma-Activated Antimicrobial Solutions Are Broad-Spectrum and Retain Their Efficacies for Extended Period of Time. Plasma Processes and Polymers, 10, 544-555. http://dx.doi.org/10.1002/ppap.201200104

[10] Poor, A.E., Ercan, U.K., Yost, A., Brooks, A.D. and Joshi, S.G. (2014) Microbial and Cellular Responses to Nonthermal Plasma-Treated Alginate Wound Dressing: Control of Multidrug-Resistant Pathogens. Surgical Infections, 15, 233- 243. http://dx.doi.org/10.1089/sur.2013.050

[11] Telang, N.V., Satpute, M.G., Niphadkar, K.B. and Joshi, S.G. (2010) An Increased Incidence of Biofilm-Producing Multidrug-Resistant Methicillin-Resistant Staphylococcus aureus in a Tertiary Care Hospital from India: A 2-Year Study. American Journal of Infection Control, 38, 165-166. http://dx.doi.org/10.1016/j.ajic.2009.07.007

[12] Standar, K., Kreikemeyer, B., Redanz, S., Munter, W.L., Laue, M. and Podbielski, A. (2010) Setup of an in Vitro Test System for Basic Studies on Biofilm Behavior of Mixed-Species Cultures with Dental and Periodontal Pathogens. PLoS ONE, 5, e13135. http://dx.doi.org/10.1371/journal.pone.0013135

[13] Gobor, T., Corol, G., Ferreira, L.E.N., Rymovicz, A.U.M., Rosa, R.T., Campelo, P.M.S. and Rosa, E.A.R. (2011) Proposal of Protocols Using D-glutamine to Optimize the 2,3-Bis(2-methoxy-4-nitro-5-sulfophenly)-5-[(phenylamino) carbonyl]-2H-tetrazolium hydroxide (XTT) Assay for Indirect Estimation of Microbial Loads in Biofilms of Medical Importance. Journal of Microbiological Methods, 84, 299-306. http://dx.doi.org/10.1016/j.mimet.2010.12.018

[14] Fridman, G., Friedman, G., Gutsol, A., Shekhter, A.B., Vasilets, V.N. and Fridman, A. (2008) Applied Plasma Medicine. Plasma Processes and Polymers, 5, 503-533

[15] Thiyagarajan, M. and Waldbeser, L. (2012) Portable Plasma Medical Device for infection Treatment. Studies in Health Technology and Informatics, 173, 518-520.

[16] De Geyter, N. and Morent, R. (2012) Nonthermal Plasma Sterilization of Living and Nonliving Surfaces. Annual Review of Biomedical Engineering, 14, 255-274. http://dx.doi.org/10.1146/annurev-bioeng-071811-150110

[17] Alkawareek, M.Y., Algwari, Q.T., Gorman, S.P., Graham, W.G., O’Connell, D. and Gilmore, B.F. (2012) Application of Atmospheric Pressure Nonthermal Plasma for the in Vitro Eradication of Bacterial Biofilms. FEMS Immunology and Medical Microbiology, 65, 381-384. http://dx.doi.org/10.1111/j.1574-695X.2012.00942.x

[18] Zelaya, A.J., Stough, G., Rad, N., Vandervoort, K. and Brelles-Marino, G. (2010) Pseudomonas aeruginosa Biofilm Inac- 
tivation: Decreased Cell Culturability, Adhesiveness to Surfaces, and Biofilm Thickness upon High-Pressure Nonthermal Plasma Treatment. IEEE Transactions on Plasma Science, 38, 3398-3403. http://dx.doi.org/10.1109/TPS.2010.2082570

[19] Schaudinn, C., Jaramillo, D., Freire, M.O., Sedghizadeh, P.P., Nguyen, A., Webster, P., Costerton, J.W. and Jiang, C. (2013) Evaluation of a Nonthermal Plasma Needle to Eliminate ex Vivo Biofilms in Root Canals of Extracted Human Teeth. International Endodontic Journal, 46, 930-937. http://dx.doi.org/10.1111/iej.12083

[20] Sladek, R.E.J., Filoche, S.K., Sissons, C.H. and Stoffels, E. (2007) Treatment of Streptococcus mutans Biofilms with a Nonthermal Atmospheric Plasma. Letters in Applied Microbiology, 45, 318-323. http://dx.doi.org/10.1111/j.1472-765X.2007.02194.X

[21] Kamgang, J.O., Briandet, R., Herry, J.M., Brisset, J.L. and Naitali, M. (2007) Destruction of Planktonic, Adherent and Biofilm Cells of Staphylococcus epidermidis Using a Gliding Discharge in Humid Air. Journal of Applied Microbiology, 103, 621-628. http://dx.doi.org/10.1111/j.1365-2672.2007.03286.x

[22] Vercaigne, L.M., Sitar, D.S., Penner, S.B., Bernstein, K., Wang, G.Q. and Burczynski, F.J. (2000) Antibiotic-Heparin lock: In Vitro Antibiotic Stability Combined with Heparin in a Central Venous Catheter. Pharmacotherapy, 20, 394399. http://dx.doi.org/10.1592/phco.20.5.394.35063

[23] Henrickson, K.J., Powell, K.R. and Schwartz, C.L. (1988) A Dilute Solution of Vancomycin and Heparin Retains Antibacterial and Anticoagulant Activities. The Journal of Infectious Diseases, 157, 600-601. http://dx.doi.org/10.1093/infdis/157.3.600

[24] Henrickson, K.J. and Dunne Jr., W.M. (1992) Modification of Central Venous Catheter Flush Solution Improves in Vitro Antimicrobial Activity. The Journal of Infectious Diseases, 166, 944-946. http://dx.doi.org/10.1093/infdis/166.4.944

[25] Ercan, U.K. and Joshi, S.G. (2013) Mechanisms Underlying Antimicrobial Efficacies of Non-Thermal Dielectric Barrier Discharge (DBD) Plasma-Treated N-Acetyl Cysteine (NAC) Solution. Ph.D. Thesis, Drexel University, Philadelphia. http://www.biomed.drexel.edu/new04/Content/news_events/display_event.cfm?EVENT_ID=969

[26] Joshi, S.G., Cooper, M., Yost, A., Paff, M., Ercan, U.K., Fridman, G., Friedman, G., Fridman, A. and Brooks, A.D. (2011) Nonthermal Dielectric-Barrier Discharge Plasma-Induced Inactivation Involves Oxidative DNA Damage and Membrane Lipid Peroxidation in Escherichia coli. Antimicrobial Agents and Chemotherapy, 55, 1053-1062. http://dx.doi.org/10.1128/AAC.01002-10

[27] Gilbert, P., Allison, D.G. and McBain, A.J. (2002) Biofilms in Vitro and in Vivo: Do Singular Mechanisms Imply Cross-Resistance? Journal of Applied Microbiology, 92, 98S-110S. http://dx.doi.org/10.1046/j.1365-2672.92.5s1.5.x

[28] Cooper, M., Fridman, G., Fridman, A. and Joshi, S.G. (2010) Biological Responses of Bacillus stratosphericus to Floating Electrode-Dielectric Barrier Discharge Plasma Treatment. Journal of Applied Microbiology, 109, 2039-2048. http://dx.doi.org/10.1111/j.1365-2672.2010.04834.x 
Scientific Research Publishing (SCIRP) is one of the largest Open Access journal publishers. It is currently publishing more than 200 open access, online, peer-reviewed journals covering a wide range of academic disciplines. SCIRP serves the worldwide academic communities and contributes to the progress and application of science with its publication.

Other selected journals from SCIRP are listed as below. Submit your manuscript to us via either submit@scirp.org or Online Submission Portal.
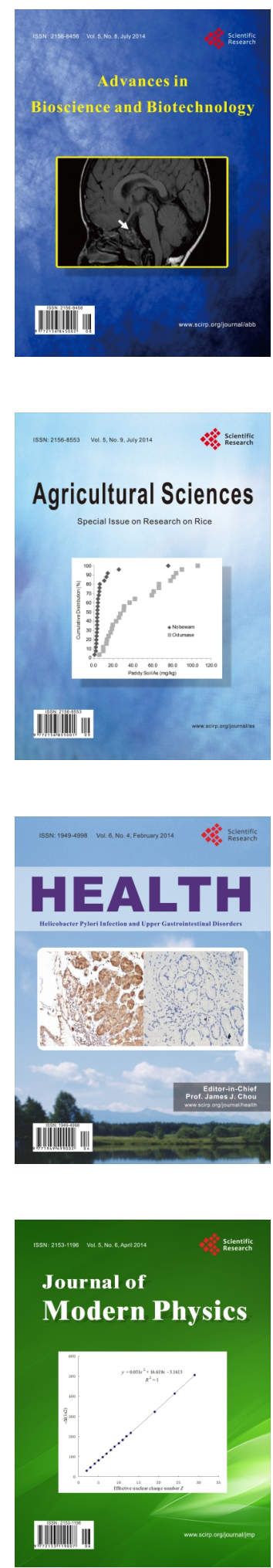
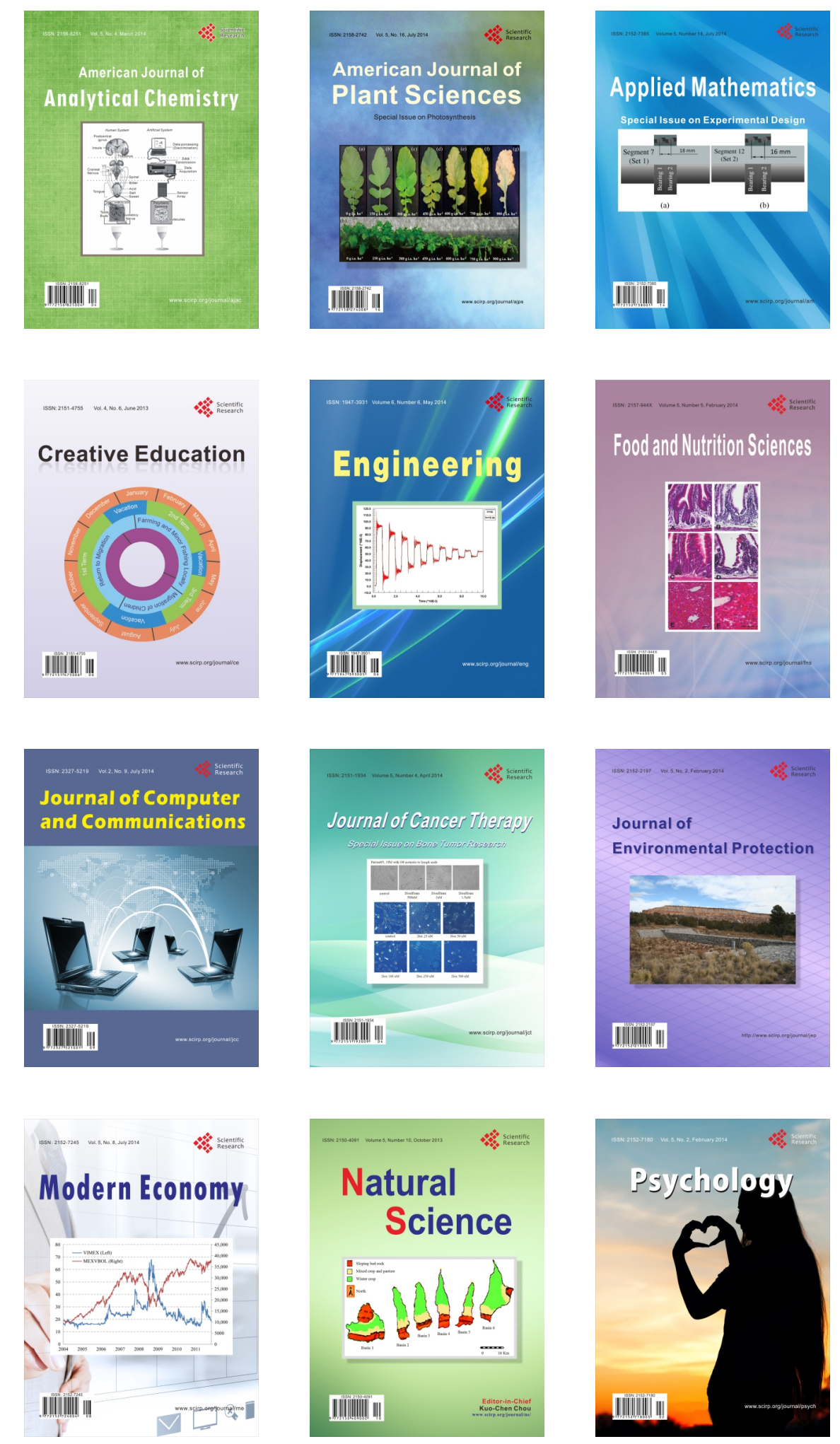